\title{
A intensificação do trabalho docente universitário: aceitações e resistências
}

\author{
The intensification of university teaching work: acceptances and resistances \\ La intensificación del trabajo docente universitario: aceptaciones y resistencias
}

ANDRÉ RODRIGUES GUIMARÃES VERA LÚCIA JACOB CHAVES

\begin{abstract}
Resumo: O objetivo do artigo é analisar como os professores universitários interagem com o processo de intensificação do trabalho. As informações foram obtidas por meio de entrevista semiestruturada com oito professores da Universidade Federal do Pará. Os resultados indicam que o conjunto dos docentes tem seu trabalho intensificado. Essa intensificação é avaliada de diferentes formas pelos professores: parte deles não a percebe criticamente, legitimando-a; outros apresentam resistências.
\end{abstract}

Palavras-chave: Trabalho docente; intensificação; universidade pública.

\begin{abstract}
The aim of this paper is to analyze how university professors interact with the process of intensification of work. The information was obtained by means of semi-structured interviews with eight professors of the Federal University of Pará. The results show that this group of professors has intensified their work. This intensification is evaluated on different ways by the professors: some of them do not notice it critically, legitimizing it; others present resistance.
\end{abstract}

Keywords: Teaching Work; intensification; public university.

Resumen: El objetivo del artículo es analizar cómo los profesores universitarios interactúan con el proceso de intensificación del trabajo. Las informaciones fueron obtenidas por medio de entrevista semiestructurada con ocho profesores de la Universidad Federal de Pará. Los resultados indican que el conjunto de docentes tiene intensificado su trabajo. Esa intensificación es evaluada de diferentes formas por los profesores: parte de ellos no la percibe críticamente, legitimándola; otros presentan resistencias.

Palabras clave: Trabajo docente, intensificación; universidad pública.

\section{INTRODUÇÃO}

Neste artigo abordamos a intensificação do trabalho docente universitário. Com base em estudos recentes e, fundamentalmente, em pesquisa empírica desenvolvida no âmbito da Universidade Federal do Pará (UFPA), procuramos analisar como os professores têm interagido com o processo de intensificação 
do trabalho decorrente da reforma da educação superior, que aproxima crescentemente a universidade pública da lógica do mercado.

Com base em Dal Rosso (2008) consideramos que a definição da intensificação do trabalho pressupõe considerarmos que: a) a intensidade do trabalho diz respeito à quantidade de energia despendida pelo trabalhador na efetividade do trabalho; b) essa intensidade está centrada no trabalhador, individual ou coletivo, independente dos meios de produção; c) o trabalhador em sua totalidade, pois considera o dispêndio de energia física, intelectual e emocional; d) na contemporaneidade capitalista a intensidade do trabalho é observada em termos de resultados (quantitativos e qualitativos) do trabalho.

$\mathrm{Na}$ parte inicial do texto fazemos apontamentos sobre a temática, evidenciando alguns estudos anteriores. Em seguida, com base na pesquisa realizada, discutimos a intensificação do trabalho docente universitário a partir de quatro pontos centrais. No primeiro, tratamos da jornada de trabalho, para identificar como a intensificação se manifesta nas distintas funções desenvolvidas pelos professores. No segundo e terceiro tópicos analisamos as atividades que levam à intensificação, considerando, respectivamente, as tarefas executadas pelos docentes no exercício de seu trabalho regular e as que são desempenhadas com remuneração extra. No último tópico, avaliamos os motivos que levam os professores, para além da necessidade de complementação salarial, a aderirem à intensificação do trabalho nas distintas funções desempenhadas na universidade.

\section{INTENSIFICAÇÃO DO TRABALHO DOCENTE NA UNIVERSIDADE: CONSIDERAÇÕES INICIAIS}

No contexto das políticas de cunho neoliberal em escala global, a educação superior vem sendo redefinida, implicando, entre outras consequências, a ampliação do espaço privado-mercantil (SGUISSARDI, 2009). No Brasil, esse processo ganha efetividade a partir da última década do século passado, particularmente com a aprovação da atual Lei 9.394/1996, de Diretrizes e Bases da Educação Nacional.

Para as instituições de educação superior públicas, particularmente as universidades, isso tem-se expressado no crescente movimento de adoção de práticas mercantis no atendimento educacional, bem como na forma de gestão. Dentre tais ações, destacam-se: "criação de fundações de direito privado; cobranças de taxas e de mensalidades em cursos de pós-graduação; corte de verbas para infraestrutura; cobranças pela prestação de serviços, entre outras" (CHAVES, 2005, p. 129). Essa crescente privatização da formação e do conhecimento produzido na universidade, na perspectiva do "capitalismo acadêmico", altera 
a própria concepção da função social da instituição, redefinindo sua cultura acadêmica (NAIDORF, 2005).

Isso implica centralmente em alterações no trabalho docente universitário. A crescente aproximação das universidades públicas aos interesses do mercado impacta diretamente a prática universitária, na condução, no conteúdo e nos resultados do trabalho dos professores. Estudos têm evidenciado que dentre as consequências centrais desse processo está a intensificação do trabalho.

Mancebo (2011) destaca que a reformulação da produção capitalista imputou também aos docentes universitários um processo de intensificação e extensão do tempo de trabalho. Aos professores são crescentemente apresentadas demandas laborais para além de suas funções tradicionais (ensino, pesquisa e extensão). Esse trabalho, nem sempre considerado nos registros oficiais, envolve a participação em órgãos colegiados, a busca de recursos para seus projetos, as demandas oriundas de órgãos reguladores/avaliadores, as comissões, os processos, os pareceres, entre outras funções. Para responder a tais exigências, os docentes precisam estender sua jornada de trabalho e, fundamentalmente, com a utilização da internet, transformam o tempo de não trabalho em tempo de trabalho. Em síntese, em decorrência da ampliação do rol de funções do professor, intensificase o trabalho docente.

\footnotetext{
Muitas funções de competência daquela categoria [técnico-administrativos] foram repassadas para o professor, com ênfase para o professor-pesquisador. Três exemplos, dentre muitos que se poderiam citar: 1) os muitos pareceres emitidos são feitos diretamente, via eletrônica, com agências de fomento ou com revistas [...]; o preenchimento de planilhas de notas de avaliação dos alunos online; e 3) a apresentação do programa da disciplina on-line, por meio de formulários eletrônicos que "obrigam" o professor a apresentar com rigor seu objetivo e estratégias para o curso que ministrará. (SILVA JR.; SGUISSARDI; SILVA, 2010, p. 19-20).
}

Dessa forma, ainda que formalmente esteja estabelecido um regime de trabalho, com horas semanais a serem cumpridas, os professores estendem essa jornada, consubstanciando um tempo invisível nos registros oficiais. Para cumprir as demandas de produtividade, impõe-se a competitividade e, para ter complementação salarial, advinda de trabalho extra, os professores precisam ampliar seu tempo de trabalho, envolvendo, inclusive, a utilização dos finais de semana, feriados e, em muitos casos, até mesmo das férias. Em todos os casos, o fundamento central dessa expansão do tempo de trabalho é a instituição da lógica produtivista e mercantil na universidade pública e, consequentemente, no trabalho docente (LEHER; LOPES, 2008). 
Essa expansão temporal da jornada foi identificada em pesquisa que investigou o trabalho docente na Universidade do Estado do Rio de Janeiro (UERJ):

\begin{abstract}
Na pesquisa realizada, muitos relatos remetem ao seguinte fato: vai-se fisicamente para casa, mas o dia de trabalho não termina, pois as "tarefas" são muitas, além das inovações tecnológicas (celulares e principalmente e-mails) possibilitarem a derrubada das barreiras entre o mundo pessoal e o mundo profissional. A jornada de trabalho, então, expandiu-se, mas nas estatísticas, esse dado tornase invisível, diante de um trabalho prescrito de 40 horas somente. Assim, não foram raros os relatos de sacrifícios de tempo livre, trabalho nos finais de semana, aproveitando das férias para adiantamento de pesquisas, dentre outros procedimentos. (MANCEBO, 2011, p. 74-75).
\end{abstract}

Para que a intensificação do trabalho docente ocorra, torna-se indispensável a participação ativa dos sujeitos no processo. Conforme destaca Lêda (2006), associada ao processo de precarização das condições e das relações laborais dos professores, presenciamos, entre esses trabalhadores, a conformação de um espirito empreendedor. Ao buscarem melhores salários e, muitas vezes, a estrutura necessária para o próprio desempenho de seu trabalho, especialmente no âmbito da pesquisa, os docentes necessitam mobilizar atributos, habilidades e dispêndios físicos, intelectuais e emocionais não necessariamente, vinculados a seu trabalho. Em geral, isso pressupõe a aproximação e submissão desses sujeitos a empresas privadas e a alunos-clientes-consumidores, por meio da venda de seus serviços.

A reflexão de Sevcenko exposta abaixo sintetiza bem esse cenário:

Nas universidades, o que prevalece é o modelo da administração eficiente, capaz de gerar seus próprios recursos estabelecendo nexos cada vez mais profundos com o mercado e com a corrida tecnológica. A eficácia de desempenho é medida em termos de sucessos estatísticos, de capitais, produtividade e visibilidade, todos conversíveis em valores de marketing para atrair novas parcerias, dotações e investimentos. [...] [Esse novo quadro] acumplicia todos nesse novo espírito de racionalidade gerencial. O professor ideal agora é um híbrido de cientista e corretor de valores. Grande parte de seu tempo deve ser dedicado a preencher relatórios, alimentar estatísticas, levantar verbas e promover visibilidade para si e seu departamento. $\mathrm{O}$ campus vai se configurando num imenso pregão. $\mathrm{O}$ gerenciamento de meio acabou se tornando fim na universidade. A idéia é que todos se empenhem, no limite de suas forças, para que também compartilhemos do inexorável destino manifesto. (Sevcenko apud IGUTI, 2002, p. 92-3).

A racionalidade gerencial destacada por Sevcenko é copiada do modelo de gestão adotado na empresa capitalista, cujo objetivo é o de produzir mais com menor custo e se funda nos critérios da eficiência, competitividade, produtividade, 
valorização dos resultados e no controle do trabalho do professor, adequando a universidade à lógica do mercado.

Sguissardi e Silva Jr. (2009), ao analisarem a intensificação do trabalho docente em universidades federais da região sudeste do Brasil, indicam que, mesmo tendo o reconhecimento da intensificação por parte dos professores, esses não apontam o fato como excesso de trabalho. "Antes, preferem avaliar a situação de muitos professores-pesquisadores e de unidades acadêmicas como realização de uma 'potência adormecida', subutilizada" (SGUISSARDI ; SILVA JR., 2009, p. 187). Em suma, há certa aceitação desse processo pelos próprios professores.

Com o intuito de compreendermos melhor como os professores tem interagido com tais mudanças, realizamos, no âmbito da $\mathrm{UFPA}^{1}$, uma pesquisa que utilizou entrevista semiestruturada (TRIVIÑOS, 1987), com oito docentes que atuam em distintas funções na universidade ${ }^{2}$.

Utilizamos a entrevista semiestruturada por permitir maior liberdade ao entrevistado e possibilitar ao pesquisador explorar pontos importantes para a análise que possam surgir no decorrer da entrevista. Além disso, ela "favorece não só a descrição dos fenômenos sociais, mas também sua explicação e a compreensão de sua totalidade" (Idem, p. 152). Para analisar as entrevistas nos fundamentamos na Análise do Discurso (BAKHTIN, 2010). Considerando especialmente o caráter ideológico do discurso, buscamos analisar as falas, a comunicação e a linguagem dos professores a partir de uma perspectiva histórico-social.

Com base nessa pesquisa, analisamos no presente artigo como os professores universitários interagem com o processo de intensificação de seu trabalho, decorrente da crescente aproximação da universidade pública à lógica mercantil.

1 A UFPA, com mais de 50 anos de existência, destaca-se na Região Amazônica por sua extensão e produção acadêmico-científica, tendo cursos de graduação e pós-graduação consolidados nas diversas áreas do conhecimento.

2 Foram entrevistados, nos meses de setembro e outubro de 2013, oito docentes que atendiam aos seguintes critérios gerais: a) ser contratados em regime de Dedicação Exclusiva; b) ser atuantes em cursos de graduação; c) ter mais de 15 anos de serviço na instituição; d) titulação de doutor. Com o intuito de selecionamos docentes com atuação em diversos setores da universidade, selecionamos professores que, atendendo aos critérios gerais, trabalhavam em: cursos de especialização autofinanciados, na pós-graduação stricto sensu, em projetos financiados por empresas privadas, nos campi do interior, na extensão universitária, em programas específicos (com recebimento de bolsas), no ensino à distância e, ainda, os que tinham atuação no movimento sindical docente. 


\section{A JORNADA DE TRABALHO: “TODO MUNDO EXTRAPOLA 40 HORAS"}

Todos os professores participantes da pesquisa destacaram que estão sobrecarregados de trabalho, com jornada efetiva para além das 40 horas contratuais. Conforme enfatiza o Docente A, na UFPA, "muita gente acaba ficando com muito mais do que 40 horas: com 60 horas, com 70 horas e tal". Essa extrapolação, ainda que seja maior para os que atuam na pós-graduação, também é destacada pelos professores que trabalham apenas em cursos de graduação.

O trabalho para além da jornada obrigatória é situação comum vivenciada pelo conjunto dos docentes, independentemente dos locais de lotação, seja em Belém ou nos campi do interior. O Docente B afirma que o conjunto dos professores do campus em que atua (no interior do Pará) ultrapassa a jornada legalmente estabelecida. Esse entrevistado ainda destaca que, para dar conta das demandas de trabalho, muitos chegam a ir para a universidade inclusive aos finais de semana: "se você chegar aqui qualquer hora da noite você encontra gente trabalhando, sábado, domingo..." (Docente B).

O Docente $\mathrm{D}$, que atua em outro campus do interior, diz que se criou nesse espaço uma "cultura da colaboração" com a universidade. Já se naturalizou o fato de os professores terem jornada efetiva acima de 40 horas: "hoje se criou uma cultura, no meu campus pelo menos, de colaboração com a Universidade". $\mathrm{Na}$ entrevista, aponta que, no semestre que estava em curso, tinha 44 horas registradas em seu Plano Individual de Trabalho (PIT) e cerca de 60 horas efetivas de trabalho, sendo isso considerado já algo normal pelo conjunto dos professores.

Os Docentes B e D ressaltam ainda que nos campi do interior as atividades desenvolvidas pelos professores são predominantemente no ensino de graduação, apesar de nos últimos anos ter crescido o número projetos de pesquisa. Essa situação faz com que muitos docentes que possuem 20 horas em seus Planos de Trabalho para a pesquisa "acabem, na realidade, só tendo 10 horas, porque acabam dando mais (há demanda muito grande!) no ensino" (Docente D). Nessas condições, o desenvolvimento da pesquisa implica mais trabalho.

Outro docente entrevistado afirma que a intensificação do trabalho é a realidade de toda a universidade. "De modo geral, em todos esses locais [campi e institutos da UFPA] é comum, de forma mais expressiva ou não, esta reclamação da sobrecarga de trabalho do professor" (Docente C). De fato, no conjunto das entrevistas, é recorrente o registro dos professores que levam trabalho para suas casas, trabalham nos finais de semana, nos feriados e até mesmo nas férias e permanecem mais de oito horas diárias na instituição. Para os professores, essa 
situação é decorrente da expansão em cursos de graduação, pós-graduação e atividades de extensão implementadas na UFPA nos últimos 15 anos.

A extrapolação das 8 horas diárias de trabalho, entretanto, na opinião de parte dos entrevistados não atinge todos os docentes. Essa é a compreensão dos professores que atuam na pós-graduação, com exceção do Docente C. Para esses docentes, "nem aquela carga horária, aquele período que deveria ficar na universidade de acordo com seu concurso, ou com seu plano, com seu contrato de trabalho, a maioria não cumpre, isso é palpável" (Docente G). Assim, somente aqueles “que 'vestem a camisa' estão sobrecarregados" (Docente H), os quais estão, nesse caso, necessariamente na pesquisa e pós-graduação. Temos, assim, divergentes opiniões formadas a partir do local de atuação dos docentes que hierarquizam as relações de trabalho, promovendo divisão da própria categoria entre os "mais" e os "menos" comprometidos com a instituição, ao mesmo tempo em que revelam a valorização da pesquisa e da pós-graduação em relação ao ensino.

Ao analisarmos o conjunto das entrevistas identificamos que as atividades responsáveis pela ampliação da jornada de trabalho, para além da categorização entre visíveis e invisíveis (MANCEBO, 2011), podem também ser classificadas em dois grupos: no primeiro estão as atividades tradicionalmente desenvolvidas e a inclusão de novas tarefas para os professores no exercício de seu trabalho regular na própria universidade; no segundo grupo estão outras atividades com remuneração complementar aos docentes.

\section{INTENSIFICAÇÃO E NOVAS ATRIBUIÇÕES: "VOCÊ TEM MAIS UMA RESPONSABILIDADE”}

Dentre as atividades que os professores desenvolvem sem qualquer remuneração extrassalarial que compõem atualmente a jornada intensificada de trabalho docente estão as demandas da gestão, o envolvimento com a pósgraduação e a pesquisa, a participação em comissões, o preenchimento de diários e outras demandas on-line bem como a ampliação dos cursos e matrículas na graduação sem o correspondente aumento do quadro docente.

Conforme destacado pelo Docente A, o professor que tem cargo administrativo, ainda que legalmente tenha suas 40 horas alocadas em tal função, caso não queira abandonar sua "carreira de pesquisador", tem que desenvolver um conjunto de atividades. Assim, é necessário que esse docente continue ministrando aulas na graduação e pós-graduação, orientando e publicando, entre outras demandas. "Então, certamente isso, se abraçado mesmo como um projeto 
profissional, vai levar a um superdimensionamento da minha carga horária. Eu vou trabalhar muito mais do que oito horas por dia" (Docente A).

Para os professores atuantes em projetos de pesquisa que estão na pósgraduação, a quantidade de trabalho e, consequentemente, o tempo despendido para responder às demandas é muito grande. "Esta sobrecarga tem aumentado, em particular, com a expansão da pós-graduação na universidade. Então, os professores que estão na pós-graduação, esses professores estão mais sobrecarregados ainda" (Docente C). Exatamente por reconhecer essa situação, a Docente B resolveu sair da pós-graduação: "eu tive problemas pessoais pelos quais eu não pude também exigir muito de mim profissionalmente [...], por questão de saúde, por questões familiares. E eu também preferi não exigir muito de mim, não ceder a isso nesse momento" (Docente B).

Para o Docente H a ampliação da jornada de trabalho na pós-graduação implica redução da carga horária na graduação. Essa situação não acontece com todos os professores, como destaca o Docente G:

Como eu tenho projeto de pesquisa, a minha carga horária deveria estar reduzida para o ensino em 20 horas, porque 20 horas para ensino e 20 horas para pesquisa. Bom, se eu já tenho 12 horas e se você considerar a preparação, isso já extrapolou as 20 horas que eu teria para fazer o ensino. Além disso, eu tenho três alunos de iniciação científica de graduação [...]. Na pós eu tenho dois alunos de mestrado e seis alunos de doutorado - além disso, eu tenho mais um pretendente ao mestrado e outro pretendente ao doutorado, que já estão iniciando uma pesquisa (e este pessoal também precisa de uma atenção, você precisa ter um plano de trabalho, um plano de estudos, você precisa sentar e discutir o que você sugere pra leitura).

Também faz parte do trabalho docente, especialmente na pós-graduação, a participação em bancas de mestrado e doutorado, sem qualquer registro nos Planos de Trabalho. Um dos docentes entrevistados ressalta que todo mês participa de, pelo menos, uma banca e que isso é um trabalho extra e não remunerado. "Mas, (imagina!) às vezes você tem, geralmente no mês de agosto, início de mês, três teses, duas teses, uma qualificação pra participar de banca. [...] Você tem um trabalho enorme e no final das contas ganha aquele 'tapinha lá': 'valeu! Obrigado pela contribuição"” (Docente $\mathrm{H}$ ).

Dentre as atividades oriundas da atuação na pós-graduação e pesquisa ainda estão as relacionadas à produção acadêmico-científica para atender aos parâmetros da CAPES. "O professor vinculado à pós-graduação, para que permaneça na pós-graduação, tem que estabelecer, se enquadrar dentro dos critérios de produtividade que a CAPES estabelece para o Programa" (Docente C). Essa questão também é ressaltada por outro entrevistado, segundo o qual o pesquisador da universidade tem como baliza regras externas, "principalmente 
da Capes, que fazem com que o pesquisador, que faz questão de manter-se como pesquisador, esteja sempre atrás de determinadas coisas. O famoso, já virou até um provérbio, 'publicar ou morrer"' (Docente A).

Mesmo para quem não ocupa cargos de gestão e não está na pósgraduação, a sobrecarga de atividades está presente. O detalhamento das atividades desempenhadas para além do PIT de um dos entrevistados mostra que muitas atividades rotineiras do trabalho dos professores da UFPA não são contabilizadas na integralização da jornada semanal, como segue:

Eu, atualmente, estou com 44 horas de PIT. Digamos que eu tenha mais, dessas 44, vamos botar mais 3 ou 4 horas desse trabalho extra, também que não é pago, que você acaba assumindo. Sem botar as comissões, que eu não estou falando, mas, por exemplo, eu tenho cinco pedidos, em casa, de crédito que eu tenho que analisar lá dos alunos que pediram nas disciplinas que eu ministro. Lançamento de nota eu tenho feito (o pior de tudo é que você ainda tem que estar todo dia abrindo o sistema que não avisa quando vai abrir, abre e fecha sistema e você tem essa preocupação ainda de estar acompanhando). Reuniões que não estão atualmente - não se quer colocar carga horária pra reunião. [...] Eu não estou nem contando as especializações, bancas que você participa também e que não está previsto em lugar nenhum [...]. Isso só pra ficar com alguns exemplos que a gente lembra no momento (Docente D).

Esse professor ainda destaca que, ao mesmo tempo em que foi reduzido o número de servidores técnico-administrativos, ampliaram-se as atividades docentes, como o lançamento das frequências e dos conceitos dos estudantes. Com o sistema on-line é o próprio professor que marca suas férias, assumindo assim novas funções burocráticas, representativas de mais trabalho. Segundo ele, "porque você tem mais uma responsabilidade, inclusive, às vezes, na tua casa, usando o teu computador, gastando a tua energia, você tem que fazer isso, tem que estar lançando tudo isso" (Docente D).

Outro docente entrevistado também destacou que, em função de atribuições burocráticas repassadas aos professores, amplia-se o trabalho extra. Para esse professor, o processo de "burocratização" da UFPA, com a proliferação da instituição de comissões para tratar de "qualquer coisa", faz com que alguns professores se sobrecarreguem ainda mais, como é o seu caso:

Aqui tem uma série de comissões: "Ah! Vai ter uma progressão", cria uma comissão; "Ah! vai ter qualquer coisa aqui", cria uma comissão. Existem colegas que fogem dessas comissões. E o que ocorre? [...] Quando você trabalha bem, você acaba trabalhando bem mais, porque, digamos assim: eu vou trabalhar numa comissão e eu faço aquele parecer bonito, faço uma coisa séria e tudo mais, e, normalmente, o Diretor da Faculdade quer um trabalho bonito e vai, só fica chamando. O Diretor da minha Faculdade não me erra, de duas em duas semanas ele me coloca em uma comissão (Docente H).

RBPAE - v. 31, n. 3, p. 567 - 586 set./dez. 2015 • 575 
$\mathrm{Na}$ mesma linha, outra entrevistada ressalta que, nos últimos anos, aumentou o número de reuniões na faculdade e instituto em que é lotada. Ainda que sejam previstas em seu PIT horas para reuniões, tal destinação é sempre inferior ao que ocorre na prática: "Nossa! O que a gente tem de hora de reunião pra decidir coisas, que embora esteja prevista reunião de Departamento em carga horária, você sempre excede isso" (Docente E).

Outra questão que contribui centralmente para a sobrecarga do trabalho docente diz respeito ao processo de expansão da universidade. No âmbito da graduação alguns dos professores entrevistados citaram políticas específicas do governo federal que induziram à expansão de cursos e matrículas, com a intensificação do trabalho docente. $\mathrm{O}$ entrevistado a seguir, ressalta que a primeira manifestação desse processo de intensificação, fundamentado na introdução da lógica produtivista dentro da universidade, foi a instituição da Gratificação de Estímulo à Docência (GED) ${ }^{3}$.

E todos os professores começaram a se preocupar com a pontuação da GED: exigia-se que se cumprisse uma série de atividades pra poder atingir uma pontuação que garantisse o salário pleno. [...] E também por conta disso uma intensificação muito grande do trabalho, porque as pessoas já não ficavam mais satisfeitas somente de fazer a pontuação. Havia uma tendência das pessoas quererem fazer muito mais do que aquela pontuação mínima: se queria sempre ultrapassar. Havia certa euforia, então, todo mundo queria, pra se sentir seguro, pontuar ao máximo, participar de muitas atividades dentro da universidade (Docente D).

Também o Programa de Apoio a Planos de Reestruturação e Expansão das Universidades Federais (REUNI) é apontado por três entrevistados como uma política, mais recente, que intensificou o trabalho docente na universidade ${ }^{4}$. O processo atual de intensificação se dá muito em função dessa política, como exemplifica a docente: "nós tínhamos um único curso que era Ciências Biológicas, nós passamos a ofertar Ciências Naturais, dobrou o número de turmas [...], então, claro que a exaustão é bem maior" (Docente B). Essa ampliação do número estudantes por turma também é observada pelo entrevistado a seguir:

A ampliação do número de vagas nos cursos já existentes (por exemplo, Economia, que era um curso que ofertava 80 vagas divididas em duas turmas, hoje oferta 100 vagas divididas em duas turmas). Eu trabalhei com o Curso

\footnotetext{
3 A criação da GED constituiu-se ação central no governo de Fernando Henrique Cardoso (19952002) para expansão das matrículas nas universidades federais, sem a contratação de professores.

4 O REUNI consubstanciou-se na política central do governo Lula da Silva (2003-2010) na expansão de cursos e matrículas nas universidades federais, sem a correspondente ampliação do corpo docente e técnico-administrativo.
}

576 - RBPAE - v. 31, n. 3, p. 567 - 586 set./dez. 2015 
de Direito durante algum tempo, com a disciplina de Economia Política, lá se formavam as turmas com 35 alunos, turmas de calouros com 35 alunos, hoje se formam turmas com 45 alunos. Num curso como Economia em que entram 50 calouros numa turma, abre-se uma turma (no Serviço Social é a mesma coisa) até com 60 alunos. Por quê? Porque você pega os 50 alunos e pega mais os alunos de repetência, então, o professor que está pegando uma turma dessas, na realidade está trabalhando por um professor e meio (do que trabalhava antes quando o professor tinha 40 alunos), agora ele está pegando uma turma com 60 alunos, ele está cumprindo a função de um professor e meio (Docente C).

Os dados expostos demonstram que não são apenas os docentes atuantes na pós-graduação que têm seu trabalho intensificado. O conjunto dos docentes vivencia a ampliação do tempo de trabalho, envolvendo atividades desempenhadas aos finais de semana, nas próprias residências dos professores, incluindo a participação em comissões, a elaboração de pareces, o lançamento de notas e frequências diretamente no sistema da universidade, a participação em bancas e o aumento das matrículas e cursos de graduação e pós-graduação. Esse processo de intensificação também é oriundo das demandas com remunerações extras, como veremos a seguir.

\section{ATIVIDADES COM REMUNERAÇÃO EXTRA: “EM JANEIRO ELE TRABALHA, EM JULHO ELE TRABALHA"}

A maioria dos professores entrevistados indicou participar ou já ter participado de atividades docentes com remuneração extra. Essas atividades correspondem especialmente à participação em cursos conveniados ou autofinanciados, em projetos financiados por empresas privadas e em programas específicos do governo federal, com pagamento de bolsas.

No caso dos docentes que participam de atividades decorrentes das parcerias com empresas e dos cursos de especialização autofinanciados, a sobrecarga de trabalho não é tida como problemática. Como o pagamento que advém dessas atividades é extraordinário, elas implicam "naturalmente" maistrabalho. $\mathrm{O}$ docente $\mathrm{H}$ indica que, especialmente quando participa de projetos financiados por empresas, sempre ultrapassa seu tempo regulamentar de trabalho. Nesse caso, para esse professor, a sobrecarga "comum" é maior ainda: "quando eu estou com estes projetos, com essas bolsas, ao invés de passar dois turnos, eu passo três turnos aqui; normalmente, eu passo três, mas aí eu ficava um tempo maior aqui" (Docente H). Da mesma forma, outro entrevistado, que atua em cursos autofinanciados, indica que "o Plano de Trabalho é ocupado com todas as tarefas da UFPA e, depois disso, de ter cumprido suas tarefas, a pessoa ao invés 
de ir para sua casa descansar se predispõe a trabalhar um pouco mais e participar de uma especialização" (Docente F).

Outra situação evidenciada se refere aos professores que atuam em programas e projetos com recebimento de bolsas com ampliação de sua jornada de trabalho, sem registro formal. Uma das entrevistadas, que atua no Plano Nacional de Formação de Professores (PARFOR), aponta que isso implica mais trabalho; porém, por ser remuneração extra é "natural" que não conte na jornada de trabalho. Considerando especificamente a ampliação da jornada de trabalho que resulta da participação nesse Programa de Formação, os depoimentos indicam que há professor, especialmente das Licenciaturas, sem férias na UFPA. "Deixou de ter férias porque os meses que seriam de férias, intervalar, ele está dando aula no PARFOR [...], e esse cara deixou de ter férias porque em janeiro ele trabalha, em julho ele trabalha e no resto dos meses ele está dando aula nos cursos regulares" (Docente C).

Essa situação também ocorre no caso dos docentes que participam de cursos conveniados com prefeituras municipais para formação de professores da Educação Básica, com recursos do Fundo Nacional de Desenvolvimento e Manutenção do Ensino Fundamental (FUNDEF). Isso indica que não apenas a "semana cristã" foi modificada pela rotina de trabalho docente ${ }^{5}$, mas também as férias dos professores foram reformatadas.

O que aconteceu também com esse tipo de contrato foi uma intensificação. Primeira consequência que a gente começou a notar é de intensificação do trabalho dos docentes, porque os docentes tinham que cumprir o PIT e, além de ter que cumprir o PIT, eles, por uma necessidade mesmo financeira, nas suas férias, aderiram a esses Programas e iam dar aula pra essas turmas - como um programa de férias, de trabalho de férias dos professores (Docente D).

Curiosamente, alguns professores não mencionaram como integrantes de suas jornadas de trabalho todas as atividades que desenvolvem. Um dos entrevistados, por exemplo, que ocupa cargo de gestão num dos institutos da UFPA não mencionou essa função ou as horas despendidas em seu exercício. Outro docente informou que não contabilizou horas para as orientações na pósgraduação. Essa desconsideração de certas atividades em suas horas de trabalho também foi destacada por outros entrevistados, particularmente quando se trata de trabalho desempenhado nos finais de semana, feriados e férias.

Nesses casos, a carga de trabalho não computada oficialmente acaba sendo assumida como "natural" para o professor. A ausência de registro e

5 Bosi (2010) destaca que na atualidade "a nova rotina de trabalho refez a semana cristã de modo que 'o sábado ainda é sexta-feira, e o domingo já é segunda-feira”' (p. 13).

578 - RBPAE - v. 31, n. 3, p. 567 - 586 set./dez. 2015 
contabilidade dessas horas tende a indicar que é trabalho e não trabalho ao mesmo tempo. Consideramos que a extrapolação da jornada regimental de trabalho é, por si só, um problema para os professores que, com a intensificação do trabalho e em condições precárias, acabam sofrendo e reduzindo o tempo de lazer, como apontam os próprios entrevistados. Essa situação é mais preocupante quando os professores "naturalizam" esse processo, seja com a indicação que isso é "inerente à profissão", seja quando "esquecem" os trabalhos feitos, ou seja, "transformam" o trabalho em não trabalho.

Para compreendermos e analisarmos melhor o processo de intensificação do trabalho docente, procuramos identificar os motivos, para além das necessidades econômicas (no caso de cursos pagos, conveniados ou outras formas de complementação salarial), que levam os docentes a assumir maiores e novas demandas laborais.

\section{ADESÃO À INTENSIFICAÇÃO: "VOCÊ ESTÁ AQUI, COMO VOCÊ NÃO PARTICIPA?”}

Para além da questão financeira, no caso de atividades com pagamento extra, há outras motivações que levam os docentes a "aceitarem" a ampliação de sua jornada, envolvendo inclusive trabalhos "voluntários". Esse envolvimento tem como eixo central a competitividade, assumida pelos próprios professores. Conforme expressa a Docente $\mathrm{B}$, quando questionada sobre os motivos que levam os docentes a essa adesão: "Essa é a pergunta que não quer calar. Eu acho que é a competição, é a competição interna, é a competição profissional de uma maneira geral. É a competição".

Especialmente para os docentes pesquisadores, essa adesão está diretamente relacionada à necessidade de reconhecimento acadêmico. Os professores assumem variadas atividades, como avaliadores de projetos ou de revista, participação em bancas, entre outras questões importantes para o seu currículo. O Docente A destaca que "vai ter uma série de atividades irrecusáveis, porque isso está compondo esse currículo. E tem a ver com a chamada de editais. Tem a ver com a minha sustentação como pesquisador".

Os professores avaliam essa questão de distintas formas. Um dos entrevistados reconhece que, no caso brasileiro, o pesquisador "é contado pelo número de artigos que ele publica, artigos que outros citam" (Docente F). Mas, para ele, o problema disso é a natureza “cartorial”, que só produz papel, visto que o interessante seria considerar o pesquisador pelo número de "patentes" adquiridas. Os Docentes G e H não fizeram crítica alguma às exigências de produção acadêmica que envolvem o trabalho docente. Outros entrevistados denunciam 
tal processo que toma conta do imaginário da maioria dos pesquisadores, limita a autonomia e intensifica o trabalho docente. $\mathrm{O}$ depoimento a seguir expressa essa crítica:

\begin{abstract}
Ou você produz em instituições, em revistas reconhecidas com Qualis, ou você não tem prestígio. É a tua moeda: ou você tem isso ou você não tem moeda pra ser reconhecido, pra ser respeitado enquanto profissional na universidade. Então, a produção passa [...] a ser para muita gente a motivação principal na carreira (para muita gente!). Eu já ouvi muito professor dizer o seguinte: ele dá aula, tudo bem! Mas, para ele, o que interessa é produzir um artigo ou dois, durante um ano, para uma revista; se ele fizer isso ele está cumprindo com o objetivo da carreira acadêmica. Então, pra muita gente é isso mesmo: produção em periódicos, de nível internacional de preferência. [...]. Quer dizer, no nosso caso na educação, não interessa se tem impacto, não interessa se tem importância social, não interessa nada, interessa que tenha lá o Qualis A1, A2 ou até B1. Isso que é bem interessante! E essa produção passou a ser feita muitas vezes de uma maneira muito mecânica, sem preocupação com a qualidade, as pessoas sem preocupação ética, muitas vezes, com a pesquisa: o que vale mesmo é produzir (Docente D).
\end{abstract}

Para uma das entrevistadas, essa lógica produtivista fundamenta-se na competitividade. Em tal processo, usando seu exemplo pessoal, aqueles que não "cedem muito", "pagam um preço alto", pois ficam de fora dessa "excelência". Essa professora percebe ainda que não são apenas os professores-pesquisadores que aceitam sem questionamentos essa lógica, trata-se de algo que invade toda a universidade. "Eu vejo assim: parece uma maneira alienada. Uma coisa cega mesmo: 'Ai! Vamos lá'. Aquele efeito do instinto de manada: 'tem que ser por aqui, então, vamos todo mundo por aqui', sem refletir o que eu estou fazendo" (Docente B). O discurso da competência e da competitividade é assumido, tomado para si, pelos próprios docentes. Para Chauí (1981), a maior letalidade desse discurso é que não se trata de uma submissão qualquer, trata-se da interiorização das regras, ou seja, de assumi-las como suas e legitimadoras de um projeto de vida. Assim, o trabalho docente passa a ser valorizado pela sua produtividade, medido em quantidades.

Como consequência desse processo, conforme apontam metade dos entrevistados, institui-se na universidade uma "cultura" de supervalorização da pesquisa, em detrimento das demais atividades, especialmente do ensino. "Então, vai-se criando um pouco essa concepção de estratificação e a valorização mesma das atividades: a gente vê uma supervalorização da produção intelectual em detrimento de outras atividades" (Docente A). Nesse sentido, até mesmo a atividade central do trabalho docente, o ensino, torna-se "perda de tempo", visto que "toma o tempo precioso que poderia ser dedicado às atividades que permitem 
acumular mais pontos. Disto pode depender o seu mestrado, o seu doutorado e o seu quinhão de poder". (SILVA, 2005, p. 88).

\begin{abstract}
Então, todo mundo hoje quer escrever artigo, todo mundo hoje tem que ser pesquisador. Essa que é uma questão interessante, que é quase uma ditadura da pesquisa. Você não pode mais ser um professor que não pesquisa. E nem todo mundo tem vontade e nem tem vocação pra ser pesquisador, mas hoje ou você é pesquisador ou não faz sentido você estar na universidade. O ser pesquisador passa a ser o critério pra tudo: se você é um pesquisador, então, por tabela, já se supõe que você seja um bom professor, que você seja qualificado. Então, se supõe também isso: tem título, produz, é qualificado! (Docente D).
\end{abstract}

Essa concepção de professor-pesquisador tem como fundamento o produtivismo acadêmico, impulsionado por agentes externos à universidade. Isso conduz necessariamente à instituição da competitividade: o "sucesso" de uns depende do "fracasso" de muitos. Uma lógica que elimina não apenas os "incapazes", mas coloca para os "vencedores" a necessidade de ir sempre adiante, "produzir e produzir" para "existir".

Cabe destacar que, para além do "status acadêmico", em alguns casos o envolvimento dos professores com a pesquisa e a pós-graduação se dá em função da compreensão do papel social que a universidade deve desempenhar. Um conjunto de docentes "que assumem mais efetivamente a universidade como um projeto mais amplo do que simplesmente ministrar aula e olham esta pósgraduação como uma forma de dar um estímulo para isso, de realizar projetos de pesquisa e uma série de outras coisas" (Docente C). Assim, a adesão ao processo em curso, com a intensificação do trabalho, é vista como o “ônus” necessário para que a universidade cumpra efetivamente sua função social.

Outra questão importante a ser destacada é que alguns professores consideram a intensificação do trabalho como inerente à profissão docente. Nessa perspectiva, o problema maior é que muitos professores não têm essa "sensibilidade". Tal compreensão é expresso em afirmações como: "Sim, mas você está aqui, como você não participa?” (Docente F). Essa motivação também é destacada por outro entrevistado que, considerando especificamente a expansão das matrículas sem a correspondente contratação docente, com o surgimento de demandas de disciplinas para além de sua carga horária regular: "eu, com toda sinceridade, não consigo entender como é que a gente não faz um esforço maior, a gente professor, alguns, pra que os estudantes não sejam prejudicados (porque ao final quem é prejudicado é o estudante) por uma falta de oferta" (Docente G). Essa naturalização da intensificação do trabalho é evidenciada em outro entrevistado ao destacar que, em função da ocupação de cargos de gestão sempre desenvolve "trabalhos voluntários". Isso se dá pelo fato de que o abandono 
de outras atividades (como as aulas e a orientação) leva ao fracasso dos seus estudantes. Para esse professor é "inescapável” da função docente o fato de trabalhar cada vez mais, para além dessa mesma obrigação contratual. O trecho a seguir é ilustrativo dessa situação:

Em geral, eu chego por volta de 7 h 30 min ou 8 horas da manhã e na maioria das vezes fico até o final do dia; permaneço aqui inclusive fazendo a minha alimentação no Restaurante Universitário, pra que eu possa ganhar esse tempo que eu não teria se fosse almoçar em casa. Durante muito tempo também eu ministrei aulas à noite e nesse período eu [...] ficava até 10h 30min ou 11 horas da noite. Quer dizer, vivendo a própria academia, que me parece extremamente importante até para que você possa ser melhor sensibilizado pelos problemas do cotidiano do ensino. [...] Parece-me que a função do professor não é chegar aqui ministrar sua aula e cuidar da sua vida lá fora; eu acho que há uma exigência de uma permanência na maioria das vezes acima do que é exigido de acordo com a lei (Docente G - grifos nossos).

Tal fala revela a intensificação do trabalho docente com a anuência de parte dos trabalhadores. O professor almoça na universidade, para não perder tempo com a refeição, passa mais de oito horas por dia na instituição e entende que é "natural", pois é inerente à função de professor universitário, trabalhar além de sua jornada. Essa avaliação também é compartilhada pelo Docente $\mathrm{F}$, ao indicar que a longa jornada "é a circunstância de ser docente", e pelo Docente $\mathrm{H}$, ao afirmar que nem todos "vestem a camisa da universidade". Na mesma perspectiva, a Docente E indica que o problema que gera a intensificação são os professores que não trabalham além de sua obrigação, pois tem "professor que se limita em fazer como ele fazia antes dessas exigências, ele vem, dá a aula dele, cumpre a carga horária e tchau!" (grifos nossos).

Enfim, para além da complementação financeira, seja pela lógica da competitividade que invade o imaginário docente, pelo projeto de universidade que defendem ou ainda, pela necessidade do professor sensibilizar-se com os estudantes, entendemos que o processo de sobrecarga e intensificação do trabalho docente, a adesão consciente ou não a tal situação decorre das condições objetivas em que se insere a universidade pública e, consequentemente, os sujeitos que nela atuam.

\section{CONSIDERAÇÕES FINAIS}

O processo de intensificação do trabalho docente universitário deve ser compreendido no contexto de transformações do mundo do trabalho e, particularmente, como consequência das "alterações ocorridas na política de 
Educação Superior, num contexto de reforma neoliberal do Estado brasileiro, em curso desde meados dos anos 1990" (MANCEBO; LIMA, 2012, p. 132). Como fundamento macroestrutural de todo esse processo está a crise estrutural do capital (MÉSZÁROS, 2009).

Em tal contexto, reduz-se o espaço e o tempo do pensamento crítico sobre a universidade pública, a função social dessa instituição e dos próprios docentes. A ausência de condições adequadas para seu trabalho, o processo de intensificação e a consequente redução do tempo livre dos professores são elementos que se relacionam diretamente e sustentam o processo de privatização e mercantilização da universidade pública.

Nos últimos anos, como resultado da expansão da universidade por meio de cursos de graduação e pós-graduação e do desenvolvimento de projetos de pesquisas e extensão, são crescentes as exigências de maior envolvimento laboral dos professores. Independente das atividades desenvolvidas, os docentes destacam a intensificação do trabalho, que exige deles, sobretudo, aceleração do ritmo de trabalho e ampliação da jornada regulamentar, inclusive com a utilização dos finais de semana, feriados e férias para cumprir demandas laborais. Isso, como vimos, é percebido pelo conjunto dos professores com distintas formas de avaliação.

Parte dos professores, no entanto, não percebe criticamente esse processo. Assim, ainda que reconheçam a intensificação de seu trabalho, ignoram, por vezes, que isso advém de uma política macroestrutural que atinge o conjunto da classe trabalhadora. Tais professores entendem que a origem do problema são os "indivíduos" que, isoladamente, não cumprem satisfatoriamente suas funções na universidade. Distante de questionarem o processo de intensificação laboral decorrente das exigências do capital, esses professores consideram tal fenômeno como inerente ao trabalho docente.

Por outro lado, há professores que avaliam de outra forma a intensificação do trabalho docente. Para estes, as exigências por maiores demandas laborais para o conjunto da categoria, em função do processo das mudanças em curso na universidade pública, na perspectiva de mercantilização das suas funções, afetam negativamente a prática pedagógica, o trabalho acadêmico desenvolvido. Tais docentes apresentam resistências à intensificação do trabalho e o entendem como consequência de mudanças macroestruturais que submetem a universidade aos interesses do mercado.

Enfim, a adesão, consciente ou não, a tal situação decorre das condições objetivas em que se insere a universidade pública, com a crescente privatização e mercantilização da formação e do conhecimento produzido. Também é parte desse movimento a aceitação dos próprios trabalhadores docentes, com maior 
envolvimento laboral, sem questionamentos, da legitimação do projeto formativo hegemônico. As respostas, aceitação e resistência, que os professores dão a esse processo também estão organicamente articuladas ao projeto de universidade e sociedade que defendem.

\section{REFERÊNCIAS}

BAKHTIN, Mikhail. Marxismo e filosofia da linguagem: problemas fundamentais do método sociológico da linguagem. 14. ed. São Paulo: Hucitec, 2010 .

BOSI, A. Avaliação, carreira e trabalho docente no ensino superior público: para onde vamos? Educere et Educare - Revista de Educação, vol. 5, n. 10, p. $1-16$, set. $/ 2010$.

CHAUÍ, M. Cultura e democracia: o discurso competente e outras falas. São Paulo: Moderna, 1981.

CHAVES, V. L. J. As feições da privatização do público na educação superior brasileira: o caso da UFPA. 2005. Tese (Doutorado em Educação) Universidade Federal de Minas Gerais, Belo Horizonte, 2005.

DAL ROSSO, Sadi. Mais trabalho! A intensificação do labor na sociedade contemporânea. São Paulo: Boitempo, 2008.

IGUTI, A. M. A traição nas relações de trabalho da universidade. Interface - Comunic., Saúde, Educ, v. 6, n. 11, p. 89-104, 2002. Disponível em: www. scielo.br/pdf/icse/v6n11/06.pdf. Acesso em: 26/05/2012.

LÊDA, D. B. Trabalho docente no ensino superior sob o contexto das relações sociais capitalistas. In: Reunião Anual da Associação Nacional de PósGraduação e Pesquisa em Educação, 29a , 2006,. Anais... Caxambu, 2006. Disponível em: www.anped.org.br. Acesso em: 10.05.2010.

LEHER, R.; LOPES, A.. Trabalho docente, carreira, autonomia universitária e mercantilização da educação. In: MANCEBO, D.; SILVA JR., J. R; OLIVEIRA, J. F. (org.). Reformas e políticas: educação superior e pós-graduação. CampinasSP: Alínea, 2008. 
MANCEBO, D. Trabalho docente na educação superior: problematizando a luta. In: DAL ROSSO, S. (Org.). Associativismo e sindicalismo em educação: organização e lutas. Brasília: Paralelo 15, 2011.

MANCEBO, D.; LIMA, K. R. S. Trabalho docente no contexto de expansão da educação superior. In: MANCEBO, D.; BITTAR, M.; CHAVES, V. L. J.(Org.). Educação superior: expansão e reformas educativas. Maringá: Eduem, 2012.

MÉSZÁROS, I. A crise estrutural do capital. São Paulo: Boitempo, 2009.

NAIDORF, J. La privatización del conocimiento público en universidades públicas. In: LEVY, B.; GENTILI, P. (Org.). Espacio público y privatizacion del conocimiento: estúdios sobre políticas universitárias en América Latina. Buenos Aires: Clacso Libros, 2005.

SGUISSARDI, V. Universidade brasileira no século XXI: desafios do presente. São Paulo: Cortez, 2009.

SGUISSARDI, V.; SILVA JR, J. R. Trabalho intensificado nas federais: pósgraduação e produtivismo acadêmico. São Paulo: Xamã, 2009.

SILVA JR. J. R.; SGUISSARDI, V.; SILVA, E. P. Trabalho intensificado na universidade pública brasileira. Universidade e Sociedade, ano XIX, n. 45, p. 9-25., jan. 2010

SILVA, A. O. A corrida pelo Lattes. In: RAMPINELLI, W. J.; ALVIM, V.; RODRIGUES, G. (org.). Universidade: a democracia ameaçada. 2. edição. São Paulo: Xamã, 2005, p. 87-96.

TRIVIÑOS, A. N. S. Introdução à pesquisa em ciências sociais: a pesquisa qualitativa em educação. São Paulo: Atlas, 1987.

ANDRÉ RODRIGUES GUIMARÃES é doutor em Educação pela Universidade Federal do Pará, professor da Universidade Federal do Amapá (UNIFAP) e coordenador do Grupo de Estudos e Pesquisas sobre Marxismo, Trabalho e Políticas Educacionais. E-mail: andre_unifap@yahoo.com.br

VERA LÚCIA JACOB CHAVES é doutora em Educação pela Universidade Federal de Minas Gerais, professora da Universidade Federal do Pará (UFPA), bolsista 
Produtividade do CNPq e coordenadora do Grupo de Estudos e Pesquisas sobre Educação Superior. E-mail: veraluciajacob@gmail.com

Recebido em novembro de 2015 Aprovado em dezembro de 2015 